\title{
Cryptos poridium sebagai Indikator Biologi dan Indeks Nsf-Wqi untuk Mengevaluasi Kualitas Air (Studi Kasus: Hulu Sungai Citarum, Kabupaten Bandung)
}

\author{
Tastaptyani Kurnia Nufutomo" dan Barti Setiani Muntalif ${ }^{2}$ \\ 1) Teknik Lingkungan, Institut Teknologi Sumatera Jl. Terusan Ryacudu, Desa Way Hui, \\ Kecamatan Jati Agung, Lampung Selatan 35365 \\ ${ }^{2)}$ Teknik Lingkungan, Institut Teknologi Bandung, Jl. Ganesha No.10, Lb. Siliwangi, Coblong, \\ Kota Bandung, Jawa Barat 40132 \\ E-mail:tastaptyani@gmail.com
}

\begin{abstract}
Abstrak
Kualitas air yang menurun di Hulu Sungai Citarum dapat disebabkan oleh banyak faktor. Faktorfaktor tersebut dapat diketahui dari parameter fisika, kimia dan biologi. Parameter biologi yang digunakan untuk mengevaluasi kualitas air adalah mikroorganisme patogen yang menimbulkan penyakit di sistem pencernaan seperti diare akut, yaitu Coliform dan Cryptosporidium. Tujuan penelitian ini adalah untuk mengetahui status kualitas air di Hulu Sungai Citarum dengan indeks kualitas air NSF-WQI, mengetahui hubungan dan pengaruh parameter fisik dan kimia air terhadap parameter biologi, menentukan faktor utama dari parameter air yang paling berpengaruh dan mengetahui hubungan serta pengaruh faktor utama tersebut terhadap Cryptosporidium. Metode yang digunakan adalah mengambil sampel di tiap stasiun dengan composite, mengidentifikasi dan analisis Coliform dengan MPN dan identifikasi Crytosporidium dengan Ziehl Neelsen staining, kemudian menganalisis parameter kimia dan fisika dengan indeks NSF-WQI, lalu data tersebut diolah menggunakan metode statistik PCA. Hasil pengukuran kualitas air berdasarkan NSF-WQI adalah kualitas air di Hulu Sungai Citarum termasuk kategori buruk dan medium. Keberadaan Cryptosporidium di Hulu Sungai Citarum disebabkan oleh 2 (dua) faktor utama, yaitu faktor pertama terdiri dari DO, turbiditas, $\mathrm{NO}_{2}, \mathrm{NH}_{4}$ dan total Colifom, sedangkan faktor kedua terdiri dari TSS, $\mathrm{COD}$ dan $\mathrm{PO}_{4}$. Kedua faktor tersebut tidak signifikan dengan keberadaan Cryptosporidium di Hulu Sungai Citarum.
\end{abstract}

Kata kunci: Cryptosporidium, Hulu Sungai Citarum, Indeks NSF-WQI, Kualitas Air

\begin{abstract}
The decreased water quality in the upstream of Citarum River can be caused by many factors. The parameter of physical, chemical and biological can be used to determine the causal factors of the diminishing water quality. The two biological parameters used are the Coliform and the Cryptosporidium which are the pathogenic microorganisms causing the disease in the digestive system such as acute diarrhea. The aims of this study were to determine the water quality status using National Sanitation Foundation-Water Quality Index (NSF-WQI), determine the correlation and the influence of the parameter of physical and chemical with the biological parameter, determine the main causal factors of water parameter that most influence the Cryptosporidium population, and determine the correlation and the influence of the main causal factors of water parameter againts the Cryptosporidium population. The methods of this research are water sampling from each stations using composite sampling technique, the MPN terchnique to identify and analyze the Coliform, the Ziehl Neelsen staining technique to identify the Cryptosporidium, the NSF-WQI to analyze the water physical and chemical parameters, and the statistical method of PCA. According to NSF-WQI results the water quality in the upstream of Citarum River is lied within medium category and bad category. The presence of Cryptosporidium in the upstream of Citarum River is caused by two main factors. The first main causal factors are influenced by DO, turbidity, $\mathrm{NO}_{2}, \mathrm{NH}_{4}$ and Coliform total, and the second main factors are influenced by TSS, COD, and $\mathrm{PO}_{4}$. Although these factors formed are not significant with the presence of Cryptosporidium in the upstream Citarum River.
\end{abstract}

Keywords: Cryptosporidium, NSF-WQI Index, Upstream Citarum River, Water Quality

PENDAHULUAN

Sungai Citarum merupakan sungai terpanjang dan terbesar di provinsi Jawa
Barat yang sangat mempengaruhi kehidupan masyarakat disekitarnya. Sungai Citarum mengalir dari hulu Gunung Wayang 
selatan, Kota Bandung, dan bermuara di laut Jawa. Saat ini terjadi penurunan kualitas air di Sungai Citarum dimana aliran air sungai tersebut melewati daerah pemukiman, peternakan dan pertanian, yang berkontribusi atas masuknya limbah dari hasil kegiatan antropogenik ke dalam aliran sungai (Muntalif dkk., 2008).

Air sungai yang terkontaminasi oleh limbah yang berupa feses dari hasil ekskresi manusia dan hewan dapat turun kualitasnya. Hal ini disebabkan oleh mikroorganisme patogen yang berada di badan air sungai dan dapat menjadi indikasi penyebab dari penyakit saluran pencernaan. Mikroorganisme patogen yang ditemukan di badan air selain Coliform adalah protozoa Cryptosporidium. Jika mengkonsumsi air yang tercemar oleh oosit protozoa Cryptosporidium, maka mikroorganisme ini dapat menyerang sistem pencernaan manusia secara akut hingga berefek kematian (Sunnotel dkk., 2006). Transmisi oosit protozoa Cryptosporidium bersumber dari emisi air limbah yang berupa hasil eksresi manusia ataupun hewan, dan dari pengelolaan air limbah dan emisi nonpoint yang berupa air limpasan hujan yang membawa buliran tanah ke badan air (Hofstra dkk., 2013).

Menurut Baldurson S., dan Karanis P (2011) berdasarkan laporan dari setiap negara pada periode Januari 2004 hingga Desember 2010, parasit protozoa Cryptosporidium merupakan salah satu wabah penyakit pada manusia dan salah satu agen parasit yang terbesar di badan air di seluruh dunia dengan presentase $60,3 \%$. Hal ini diikuti oleh Giardia lambia sebesar $35,2 \%$ dan protozoa lainnya sebesar $4,5 \%$. Wabah parasit Cryptosporidium terbesar terjadi di Milwaukee, Amerika Serikat, pada tahun 1993, dimana saat itu terdapat 400.000 orang terjangkit oleh parasit Cryptosporidium yang mengkontaminasi sumber air minum yang diduga kurangnya perawatan dan pengelolaan di bagian water treatment plantnya (Lisle dan Rose, 1995). Di Thailand protozoa Cryptosporidium dan Giardia ditemukan didalam sampel yang diambil dari waduk, sungai, dan penelitian ini merupakan langkah awal dan saran untuk mengkontrol kualitas air di sumbersumber air demi kesehatan dan keselamatan masyarakat Thailand (Srisuphanunt dkk., 2010). Maksud penelitian ini adalah untuk mengetahui kualitas air di hulu Sungai Citarum, Kabupaten Bandung, dan mengetahui faktor utama yang paling berpengaruh dari parameter kualitas air terhadap keberadaan
Cryptosporidium di hulu Sungai Citarum. Tujuan penelitian ini: (1) mengetahui status kualitas air di hulu Sungai Citarum dengan NSF-WQI, (2) mengetahui hubungan dan pengaruh parameter fisika dan kimia air terhadap parameter biologi air (bakteri Coliform dan protozoa Cryptosporidium), (3) menentukan faktor utama dari parameterparameter kualitas air yang paling berpengaruh terhadap Cryptosporidium, dan (4) mengetahui hubungan serta pengaruh faktor utama yang telah ditentukan terhadap Cryptosporidium di perairan hulu Sungai Citarum.

\section{METODOLOGI PENELITIAN}

Lokasi sampling penelitian berada di aliran sungai Citarum bagian hulu, yaitu dari Situ Cisanti hingga ke desa Wangisagara. Lima stasiun pengambilan sampel air diantaranya yaitu Situ Cisanti, aliran sungai di kampung Cikitu, aliran sungai di kampung Babakan, aliran sungai di Maruyung dan aliran Sungai di Wangisagara. Peta lokasi terlihat pada Gambar 1. Sebelum penelitian dilakukan, studi literatur dan survei lapangan dilakukan untuk mengidentifikasi masalah. Setelah itu dilakukan analisis kualitas air berdasarkan parameter fisika, kimia dan biologi pada sampel air di lima stasiun pengambilan sampel tersebut.

Pengambilan sampel air dilakukan menggunakan metode composite sampling dengan volume air sebanyak \pm 1 Liter. Selain itu, pengambilan sampel air lainnya dilakukan sebanyak $1 \mathrm{ml}$ dan harus diawetkan menggunakan $\mathrm{H}_{2} \mathrm{SO}_{4}$ serta didinginkan pada suhu $4^{\circ} \mathrm{C}$. Pengukuran parameter fisika kualitas air dapat diukur secara in situ dan parameter kimia lainnya dapat diukur secara in situ dan secara ex situ di Laboratorium Kualitas Air Teknik Lingkungan, Fakultas Teknik Lingkungan dan Sipil, ITB. Pengambilan sampel air untuk biologi dilakukan dengan cara random sampling. Untuk bakteri coliform, proses sampling dilakukan dengan cara memasukkan air ke dalam botol steril bervolume $100 \mathrm{ml}$. Sedangkan untuk protozoa Cryptosporidium, proses sampling dibantu dengan menggunakan alat plankton net berukuran mesh sebesar $30 \mu \mathrm{m}$, yang proses penyaringannya dilakukan secara vertikal dan horizontal dengan volume air sebanyak $100 \mathrm{~L}$. Hasil saringan tersebut dimasukkan ke dalam botol sampel $20 \mathrm{ml}$ dan diberikan iodine sebanyak 5 tetes dan 1 $\mathrm{ml}$ formalin $4 \%$.

Sampel-sampel air ini akan dianalisis di Laboratorium Mikrobiologi Teknik Lingkungan, Fakultas Teknik 
Lingkungan dan Sipil, ITB. Analisis parameter kualitas air tersebut dilakukan sesuai dengan standard methods for the examination of water and waste water (APHA, 2012) dan selanjutnya hasil tersebut akan dibandingkan dengan baku mutu kualitas air di Indonesia, yaitu PP No. 82 tahun 2001.

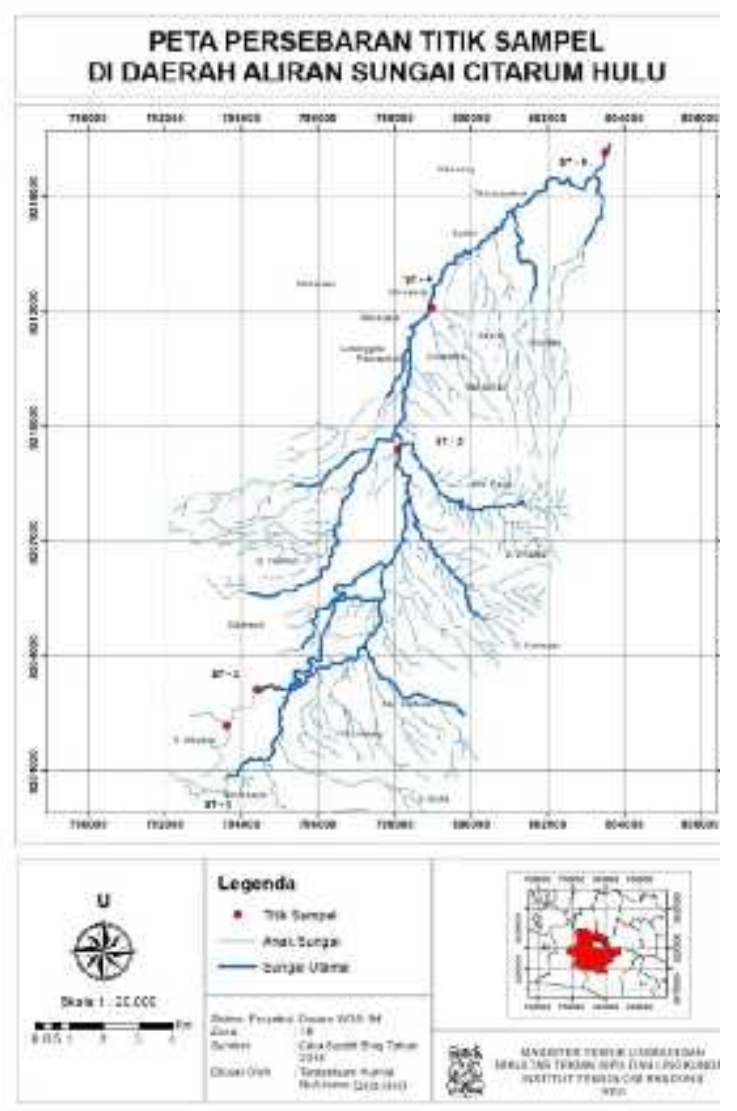

Gambar 1. Peta lokasi sampling di Hulu Sungai Citarum (Faza, 2015)

Analisis bakteri Coliform dilakukan dengan menggunakan metode MPN (most probable number), yaitu menghitung jumlah perkiraan terdekat bakteri. Analisis ini dilakukan dengan cara melakukan tiga tahapan uji, diantaranya adalah uji pendugaan (presumptive test), uji penetapan (confirmed test) dan uji kelengkapan (complete test). Uji pendugaan dilakukan dengan tujuan untuk menentukan kehadiran bakteri golongan coli dan untuk mendapatkan indeks atau nilai jumlah perkiraan terdekat organisme golongan coli dari sampel air. Uji pendugaan dilakukan dengan menggunakan media kaldu laktosa dan tabung durham yang setelah itu diinkubasi pada suhu $35^{\circ} \mathrm{C}$ dalam waktu 1 hingga 2 x 24 jam. Uji penetapan dilakukan dengan tujuan untuk memastikan kehadiran bakteri golongan coli pada sampel air yang telah memberikan hasil positif pada uji pendugaan sebelumnya. Uji ini menggunakan media EMB dan diinkubasi pada suhu $35^{\circ} \mathrm{C}$ dalam waktu $1-2$ x 24 jam. Uji kelengkapan dilakukan untuk mengkonfirmasi bakteri golongan coli dalam sampel air dan merupakan uji terakhir sampel air. Uji ini menggunakan media ECB dan diinkubasi pada suhu $44^{\circ} \mathrm{C}$ selama $1-2$ $x 24$ jam.

Protozoa Cryptosporidium akan diidentifikasi dengan cara modifikasi pewarnaan asam dari Ziehl Neelsen dan kemudian dilakukan perhitungan jumlah protozoa pada sampel tersebut. Sebelum dilakukan pewarnaan, sampel air akan dibuat apusan terlebih dahulu di kaca preparat. Setelah itu apusan melalui proses pewarnaan asam dengan bahan karbol fukhsin (campuran antara Basic fuchsin, 0,3 gr, ethanol 95\%, $10 \mathrm{ml}$, dan fenol $5 \mathrm{ml}$ ). Setelah dilakukan pewarnaan, apusan (smear) dilidahapikan di atas bunsen selama \pm 1 menit dengan catatan tidak terlalu panas dalam memanaskannya, yaitu sampai terlihat uap (vapour) dari karbol fuchsinnya saja. Setelah itu, apusan dibilas dengan aquadest dan diberikan decolorizing solvent (ethanol 95\%, 0,3 gr, dan $\mathrm{HCl}$ terkonsentrasi) sebanyak $3 \mathrm{ml}$, lalu dibilas kembali dengan aquadest. Tahap terakhir adalah memberikan pewarna counterstain (methylene blue chloride, 0,3 gr, dan distilated water, $100 \mathrm{ml}$ ). Setelah itu tunggu sekitar 20-30 detik sampai warna menyerap, dan bilas dengan aquadest kembali.

Metode pewarnaan ini memiliki kelebihan dan juga kekurangannya. Metode Ziehl Neelsen Stain merupakan metode pewarnaan asam sederhana yang mudah dilakukan, namun memiliki kapasitas sensitivitas yang rendah atau tidak spesifik dalam identifikasinya sehingga dapat mewarnai parasit protozoa lainnya seperti Isopora dan Cyclospora (Sunnotel dkk., 2006).

Indeks kualitas air digunakan untuk menentukan kualitas perairan berdasarkan parameter fisika dan kimia secara deskriptif berdasarkan angka indeks (Persamaan 1) dengan menggunakan metode NSF-WQI (Marganof, 2007). Setelah diketahui indeks nya, kisaran nilai bobot NSF-WQI dan kriteria dari kualitas lingkungan akan dapat diketahui (Oram, 2004).

$$
\mathrm{NSF}=\sum_{[-1}^{\mathrm{n}} w_{[\mathrm{C}} \cdot I_{[} \quad(\text { Persamaan } 1)
$$

Dimana, NSF adalah hasil indeks kualitas air dengan skala 0-100; Wi adalah konstanta pembobot ke-i yang diperoleh dengan menggunakan bobot yang telah diterapkan oleh NSF-WQI; li merupakan nilai sub 
indeks karakteristik ke-i yang diperoleh dengan menggunakan sub-indeks yang diterapkan oleh NSF-WQI.

Analisis data secara statistik dilakukan dengan menggunakan software SPSS ver.22. Langkah pertama untuk mengetahui hubungan variabel bebas dan variabel terikat dilakukan dengan menggunakan metode korelasi pearson dan spearman. Korelasi pearson digunakan untuk menduga adanya hubungan parameter fisika dan kimia dari kualitas air dengan parameter biologi, dengan syarat data yang digunakan berdistribusi normal. Korelasi spearman digunakan untuk mendeksripsikan hubungan dua variabel tanpa adanya asumsi distribusi frekuensi dan data yang digunakan berdistribusi normal. Langkah kedua adalah mengetahui faktor utama dengan cara menggunakan analisa komponen utama (PCA). PCA bertujuan untuk memberikan ringkasan informasi dari banyak variabel menjadi sedikit variabel dan dapat menjelaskan hubungan diantara variable-variabel tersebut. Langkah terakhir adalah untuk mengetahui pengaruh dari faktor utama, yaitu variabel bebas (independen), dengan variabel tak bebas (dependen) Cryptosporidium dengan menggunakan metode regresi linear berganda.

\section{HASIL DAN PEMBAHASAN \\ Parameter Fisika dan Kimia Perairan Sungai \\ Berikut merupakan hasil} pengukuran parameter fisika dan kimia perairan sungai yang dapat dilihat di Tabel 1. Berdasarkan tabel tersebut, nilai parameter fisika dan kimia telah berada diatas nilai baku mutu kualitas air PP. 82 tahun 2001 kategori kelas 2. Nilai kecepatan arus di stasiun sampling berkisar $0,3 \mathrm{~m} / \mathrm{s}-$ $1,03 \mathrm{~m} / \mathrm{s}$. Kecepatan arus dapat mempengaruhi jenis substrat dasar perairan sungai, dimana substrat tersebut dapat digunakan untuk menentukan densitas dari oosit Cryptosporidium (Faza, 2015).

Nilai suhu di stasiun sampling berkisar antara $22,64^{0} \mathrm{C}-26,43^{\circ} \mathrm{C}$. Nilai suhu yang tinggi di stasiun sampling dapat disebabkan oleh vegetasi reparian yang minim dan mengakibatkan tingginya intensitas cahaya matahari yang masuk ke dalam air, sehingga dapat mempengaruhi reaksi kimia air dan menurunkan kualitas air (Faza, 2015). Oosit Cryptosporidium dapat bertahan lama di suhu air yang dingin dan sejuk, yaitu berkisar dari $-10^{\circ} \mathrm{C}-27^{\circ} \mathrm{C}$ (Fayer dkk., 1998).

Nilai TSS pada semua stasiun sampling berkisar antara $263 \mathrm{mg} / \mathrm{l}-672 \mathrm{mg} / \mathrm{l}$. Nilai TSS tinggi dapat disebabkan oleh masuknya partikulat yang berasal dari riparin yang telah mengalami tata guna lahan seperti ladang pertanian (Faza, 2015). TSS tinggi dapat meningkatkan keberadaan oosit Cryptosporidium di perairan (Atherholt dkk., 1998).

Nilai kekeruhan pada semua stasiun sampling berkisar antara 12,2 NTU-47,5 NTU. Nilai kekeruhan tinggi dipengaruhi oleh perbedaan kecepatan arus air sungai di setiap stasiun. Pengaruh arus yang lambat akan menyebabkan akumulasi materi-materi padatan tersuspensi semakin besar (Faza, 2015). Kekeruhan yang tinggi mempengaruhi peningkatan jumlah oosit Cryptosporidium di perairan (Atherholt dkk., 1998). Nilai debit pada semua stasiun berkisar antara $0,03 \mathrm{~m}^{3} / \mathrm{s}-2,03 \mathrm{~m}^{3} / \mathrm{s}$. Nilai debit tinggi diperkirakan karena air limpasan permukaan dan curah hujan.

Nilai $\mathrm{pH}$ pada semua stasiun berkisar antara 7,78-8,16. Nilai pH tinggi dapat diperkirakan karena suhu, fotosintesis, respirasi, DO, dan keberadaan ion-ion (Izzati, 2008). Nilai pH untuk biota akuatik dapat hidup di perairan berkisar 78,5 bersifat netral dan alkali, oleh karena itu oosit Cryptosporidium dapat hidup di perairan.

Tabel 1. Parameter fisika dan kimia

\begin{tabular}{lccccccccc}
\hline Parameter & Unit & $\begin{array}{l}\text { Batas baku } \\
\text { mutu Kelas } \\
\text { 2 PP No.82 } \\
\text { Th.2001 }\end{array}$ & St.1 & St.2 & St.3 & St.4 & St.5 & Keterangan \\
\hline $\begin{array}{l}\text { Kecepatan } \\
\text { arus } \\
\text { Suhu }\end{array}$ & $\mathrm{m} / \mathrm{s}$ & - & 0,41 & 0,30 & 0,96 & 1,03 & 0,45 & - \\
TSS & mg/l & Deviasi 3 & 26,43 & 23,39 & 22,64 & 23,71 & 24,71 & $\begin{array}{l}\text { Deviasi suhu dari } \\
\text { keadaan ilmiah } \\
\text { untuk } \\
\text { pengolahan air } \\
\text { minum } \leq 5000 \\
\text { mg/l }\end{array}$ \\
Kekeruhan & NTU & 15 & 12,2 & 47,5 & 30,2 & 28,3 & 19,9 & -
\end{tabular}




\begin{tabular}{|c|c|c|c|c|c|c|c|c|}
\hline Parameter & Unit & $\begin{array}{c}\text { Batas baku } \\
\text { mutu Kelas } \\
2 \text { PP No.82 } \\
\text { Th.2001 }\end{array}$ & St.1 & St.2 & St.3 & St.4 & St.5 & Keterangan \\
\hline Debit & $\mathrm{m}^{3} / \mathrm{s}$ & - & 0,03 & 0,13 & 0,13 & 2,03 & 1,56 & - \\
\hline $\mathrm{pH}$ & - & $6-9$ & 8,16 & 7,78 & 8,06 & 8,05 & 7,78 & - \\
\hline BOD & $\mathrm{mg} / \mathrm{l}$ & 3 & 6,1 & 6,24 & 3,16 & 2,65 & 4,61 & - \\
\hline \multirow{2}{*}{$\begin{array}{l}\text { COD } \\
\text { DO }\end{array}$} & \multirow{2}{*}{$\mathrm{mg} / \mathrm{l}$} & 25 & 26,24 & 105,18 & 2,42 & 26,33 & 33,68 & \multirow{4}{*}{$\begin{array}{l}\text { - } \\
\text { mingka batas } \\
\text { - } \\
\text { Kandungan } \\
\text { amonia bebas } \\
\text { untuk ikan yang } \\
\text { peka } \leq 0,02 \mathrm{mg} / \mathrm{l}\end{array}$} \\
\hline & & 4 & 10,68 & 5,59 & 6,69 & 7,83 & 8,07 & \\
\hline \multirow[t]{2}{*}{$\begin{array}{l}\mathrm{PO}_{4} \\
\mathrm{NH}_{4}\end{array}$} & \multirow[t]{2}{*}{$\begin{array}{l}\mathrm{mg} / \mathrm{l} \\
\mathrm{mg} / \mathrm{l}\end{array}$} & 0,2 & 2,37 & 2,73 & 2,42 & 2,43 & 2,39 & \\
\hline & & - & 7,81 & 8,14 & 7,85 & 7,84 & 7,82 & \\
\hline \multirow{2}{*}{$\begin{array}{l}\mathrm{NO}_{3}-\mathrm{N} \\
\mathrm{NO}_{2}-\mathrm{N}\end{array}$} & \multirow{2}{*}{$\begin{array}{l}\mathrm{mg} / \mathrm{l} \\
\mathrm{mg} / \mathrm{l}\end{array}$} & 10 & 29,09 & 30,19 & 32,62 & 3,61 & 29,36 & \multirow{2}{*}{$\begin{array}{l}\text { Untuk } \\
\text { pengolahan air } \\
\text { minum } \leq 1 \mathrm{mg} / \mathrm{l}\end{array}$} \\
\hline & & 0,06 & 0,664 & 0,687 & 0,682 & 0,679 & 0,663 & \\
\hline
\end{tabular}

Nilai BOD pada semua stasiun berkisar antara 2,65 mg/l-6,24 mg/l. Nilai BOD tinggi dapat diperkirakan karena banyaknya senyawa organik di dalam perairan karena proses dekomposisi.

Nilai COD pada semua stasiun berkisar antara 2,42 mg/l-105,18 mg/l. Nilai COD tinggi dapat disebabkan oleh banyaknya bahan-bahan pencemar yang masuk ke dalam perairan khususnya limbah rumah tangga, limbah pertanian, dan limbah peternakan.

Nilai DO pada semua stasiun berkisar antara $5,59 \mathrm{mg} / \mathrm{l}-10,68 \mathrm{mg} / \mathrm{l}$. Nilai DO dapat dipengaruhi dari proses fotosintesis, suhu, dan agitasi. Nilai $\mathrm{PO}_{4}$ pada semua stasiun berkisar antara 2,37 $\mathrm{mg} / \mathrm{l}-2,73 \mathrm{mg} / \mathrm{l}$. Nilai akumulasi fosfat diperairan ini dapat disebabkan dari kegiatan pertanian dan peternakan.

Nilai $\mathrm{NO}_{3}-\mathrm{N}$ pada semua stasiun berkisar antara 29,09 mg/l - 32,62 mg/l. Tingginya nitrat diakibatkan dari limbah pertanian baik cair atau padat yang masuk ke badan air. Nilai $\mathrm{NH}_{4}$ pada semua stasiun berkisar antara $7,81 \mathrm{mg} / \mathrm{l}-8,14 \mathrm{mg} / \mathrm{l}$. Tinggi rendah amonia dipengaruhi dari banyaknya kandungan senyawa organik yang diurai oleh bakteri yang tidak dapat teroksidasi menjadi nitrit dan nitrat.

Nilai $\mathrm{NO}_{2}-\mathrm{N}$ pada semua stasiun berkisar antara 0,663 mg/l - 0,687 mg/l. Tinggi rendahnya nitrit dapat disebabkan dari DO, suhu, $\mathrm{pH}$, konsentrasi ammonia dan nitrat, dan waktu retensi yang dibutuhkan bakteri untuk merombak amonia.

\section{Parameter Biologi}

Pada Gambar 2 dapat dilihat hasil pengukuran untuk parameter biologi di Hulu
Sungai Citarum. Di lokasi 1 nilai rata-rata jumlah Total Coliform dan Fecal Coliform adalah 327 MPN/100 ml dan 115 MPN/100 $\mathrm{ml}$, untuk oosit Cryptosporidium adalah 211 sel/100L. Pada lokasi 2 terlihat peningkatan jumlah Total Coliform dan Fecal Coliform, masing-masing nilainya adalah 1100 MPN/100 ml dan 357 MPN/100 ml. Namun, terjadi penurunan jumlah oosit Cryptosporidium dengan jumlah rata-rata 169,5 sel/100L. Pada lokasi 3, ketika Total Coliform menurun jumlahnya, yaitu 741 MPN/100ml, jumlah oosit Cryptosporidium meningkat dengan jumlah rata-rata 508.375 sel/100L, serta jumlah Fecal Coliform meningkat dengan jumlah rata-rata 423 MPN/ $100 \mathrm{ml}$. Pada lokasi 4 semua parameter mengalami penurunan. Jumlah rata-rata untuk masing-masing parameter adalah $464 \mathrm{MPN} / 100 \mathrm{ml}$ untuk total Coliform, 228 MPN/100ml untuk Fecal Coliform, dan 458 sel/100L untuk oosit Cryptosporidium. Pada lokasi terakhir, yaitu stasiun 5, jumlah Total Coliform dan Fecal Coliform mengalami penurunan, namun jumlah oosit Cryptosporidium mengalami peningkatan. Jumlah oosit Cryptosporidium tersebut adalah 679.375 sel/100L. Sedangkan jumlah rata-rata untuk total Coliform adalah 332 MPN/100L dan untuk Fecal Coliform adalah 239 MPN/100ml. Perbedaan dalam parameter biologi di setiap stasiun dapat disebabkan oleh beberapa faktor. Thurman dkk. (1998) mengatakan bakteri Coliform tidak memiliki pengaruh terhadap Cryptosporidium di badan air. Hal ini disebabkan oleh Cryptosporidium dapat terisolasi di sedimen dan tersuspensi, atau terdapat pada air limpasan yang membawa tanah yang terkontaminasi dengan kotoran hewan atau 
manusia, serta adanya pengadukan yang terjadi dari kolom air ke badan air oleh aliran sehingga menyebabkan sedimen terdistribusi dan meningkatkan kekeruhan di perairan.

\section{Penilaian Kualitas Air Berdasarkan NSF- WQI}

Gambar 3 menunjukkan indeks kualitas air (NSF-WQI) hulu Sungai Citarum pada setiap stasiun sampling ke dalam kategori buruk dan kategori sedang. Nilai indeks pada tiap stasiun berkisar antara skala 47,65 - 59,47. Jika semakin tinggi nilai NSF-WQI, maka semakin baik kualitas perairan tersebut. Sedangkan, jika nilai tersebut rendah, maka semakin buruk kualitas perairan tersebut. Kondisi perairan yang buruk dapat menyebabkan terjadinya eutrofikasi perairan yang akan mempengaruhi kehidupan perairan sekitar.

\section{Hubungan Parameter Fisika dan Kimia Air Terhadap Parameter Biologi}

Pada Tabel 3 nilai korelasi parameter fisikokimia terhadap parameter Total Coliform dan Faecal Coliform menunjukkan hasil yang lebih signifikan dibandingkan dengan korelasi parameter fisikokimia terhadap parameter Cryptosporidium. Parameter fisikokimia yang menunjukkan hasil yang signifikan terhadap Total Coliform adalah DO, turbiditas, $\mathrm{COD}, \mathrm{NO}_{2}$ dan $\mathrm{PO}_{4}$, sedangkan untuk Faecal Coliform adalah DO. Nilai korelasi DO untuk Total Coliform dan Faecal Coliform memiliki nilai negatif dibandingkan dengan nilai korelasi fisikokimia lainnya. Nilai negatif ini menunjukkan bahwa adanya hubungan yang berbanding terbalik antara DO terhadap Total Coliform dan Faecal

\section{Coliform}

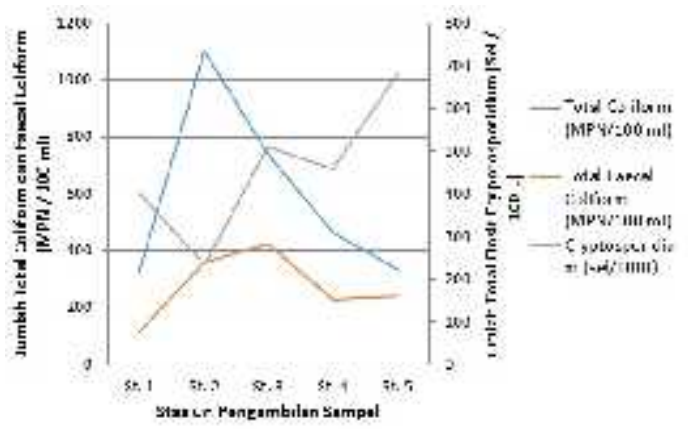

Gambar 2. Jumlah oosit Cryptosporidium di Hulu Sungai Citarum

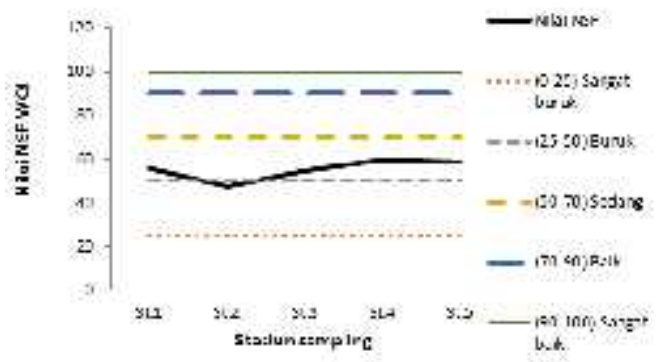

Gambar 3. Grafik NSF-WQI Hulu Sungai Citarum

Faktor-Faktor Kualitas Air yang

Mempengaruhi Cryptosporidium mempengaruhi

Terdapat dua factor utama yang Cryptosporidium. Faktor ini ditentukan dari nilai eigen value dengan nilai faktor kesatu (F1) sebesar 62,703\% dan faktor kedua (F2) sebesar 78,263\%. Kedua faktor tersebut dianggap sudah cukup mewakili variabel parameter air terhadap keberadaan Cryptosporidium. Masingmasing faktor tersebut memililiki loading factor yang didapat dari nilai rotated component matrix. Sehingga, faktor pertama dipengaruhi oleh DO, Turbiditas, $\mathrm{NO}_{2}, \mathrm{NH}_{4}$ dan total Coliform, sedangkan untuk faktor kedua dipengaruhi oleh TSS, COD dan $\mathrm{PO}_{4}$.

Tabel 2. Nilai korelasi pearson fisikokimia terhadap parameter biologi

\begin{tabular}{lcccccc}
\hline & Total Coliform & & \multicolumn{2}{c}{ Faecal Coliform } & \multicolumn{2}{c}{ Cryptosporidium } \\
\hline Parameter & $\begin{array}{c}\text { Nilai } \\
\text { Korelasi }\end{array}$ & $\begin{array}{c}\text { Nilai } \\
\text { Signifikan }\end{array}$ & $\begin{array}{c}\text { Nilai } \\
\text { Korelasi }\end{array}$ & $\begin{array}{c}\text { Nilai } \\
\text { Signifikan }\end{array}$ & $\begin{array}{c}\text { Nilai } \\
\text { Korelasi }\end{array}$ & $\begin{array}{c}\text { Nilai } \\
\text { Signifikan }\end{array}$ \\
\hline Kecepatan & $-1,07$ & 0,654 & $-0,333$ & 0,151 & 0,102 & 0,669 \\
arus & $-0,210$ & 0,375 & $-0,233$ & 0,322 & 0,344 & 0,137 \\
Debit & $-0,406$ & 0,076 & 0,001 & 0,996 & $-0,277$ & 0,236 \\
Suhu & 0,658 & 0,002 & 0,233 & 0,322 & 0,040 & 0,866 \\
Turbidity & $-0,350$ & 0,130 & $-0,022$ & 0,928 & 0,016 & 0,946 \\
pH & $-0,759$ & 0,000 & $-0,564$ & 0,010 & $-0,136$ & 0,568 \\
DO & 0,234 & 0,321 & 0,402 & 0,079 & 0,025 & 0,918 \\
TSS & 0,184 & 0,438 & 0,064 & 0,789 & 0,027 & 0,912 \\
BOD & & & & & &
\end{tabular}




\begin{tabular}{lcccccc}
\hline & \multicolumn{2}{c}{ Total Coliform } & & \multicolumn{2}{c}{ Faecal Coliform } & \multicolumn{2}{c}{ Cryptosporidium } \\
\hline Parameter & $\begin{array}{c}\text { Nilai } \\
\text { Korelasi }\end{array}$ & $\begin{array}{c}\text { Nilai } \\
\text { Signifikan }\end{array}$ & $\begin{array}{c}\text { Nilai } \\
\text { Korelasi }\end{array}$ & $\begin{array}{c}\text { Nilai } \\
\text { Signifikan }\end{array}$ & $\begin{array}{c}\text { Nilai } \\
\text { Korelasi }\end{array}$ & $\begin{array}{c}\text { Nilai } \\
\text { Signifikan }\end{array}$ \\
\hline $\mathrm{COD}$ & 0,601 & 0,005 & 0,251 & 0,286 & $-0,233$ & 0,324 \\
$\mathrm{NO}_{3}$ & 0,162 & 0,496 & $-0,145$ & 0,542 & 0,036 & 0,880 \\
$\mathrm{NO}_{2}$ & 0,708 & 0,000 & 0,423 & 0,063 & 0,250 & 0,288 \\
$\mathrm{NH}_{4}$ & 0,795 & 0,000 & 0,364 & 0,115 & 0,004 & 0,986 \\
$\mathrm{PO}_{4}$ & 0,627 & 0,003 & 0,407 & 0,075 & 0,016 & 0,946
\end{tabular}

Tabel 3. Hasil uji regresi untuk Cryptosporidium

\begin{tabular}{|c|c|c|c|c|c|c|c|}
\hline \multicolumn{8}{|c|}{ Coefficients $^{\mathrm{a}}$} \\
\hline & \multirow{2}{*}{\multicolumn{2}{|c|}{ Model }} & \multicolumn{2}{|c|}{$\begin{array}{c}\text { Unstandardized } \\
\text { Coefficients }\end{array}$} & \multirow{2}{*}{$\begin{array}{c}\begin{array}{c}\text { Standardized } \\
\text { Coefficients }\end{array} \\
\text { Beta }\end{array}$} & \multirow[t]{2}{*}{$\mathrm{t}$} & \multirow{2}{*}{ Sig. } \\
\hline & & & $\mathrm{B}$ & Std. Error & & & \\
\hline \multirow{3}{*}{1} & (Constant) & & 455,850 & 60,640 & & 7.517 & 0,000 \\
\hline & $\begin{array}{c}\text { REGR factor score } \\
\text { analysis } 1\end{array}$ & 1 for & 28,391 & 62,216 & 0,109 & 0,456 & 0,654 \\
\hline & $\begin{array}{c}\text { REGR factor score } \\
\text { analysis } 1\end{array}$ & 2 for & $-28,898$ & 62,216 & $-0,111$ & $-0,464$ & 0,648 \\
\hline
\end{tabular}

Tabel 4. Koefisien determinasi untuk Cryptosporidium

\begin{tabular}{ccccc}
\hline Model & $\mathrm{R}$ & $\mathrm{R}$ Square & $\begin{array}{c}\text { Adjusted } \mathrm{R} \\
\text { Square }\end{array}$ & $\begin{array}{c}\text { Std. Error of the } \\
\text { Estimate }\end{array}$ \\
\hline 1 & $0,156^{\mathrm{a}}$ & 0,024 & $-0,090$ & 271,191 \\
\hline
\end{tabular}

a. Predictors:(Constant), REGR factor score 2 for analysis 1, REGR factor score 1 for analysis 1

b. Dependent Variable: Protozoa

Tabel 5. Hasil uji regresi untuk bakteri Coliform

\begin{tabular}{cccccc}
\hline Model & \multicolumn{2}{c}{$\begin{array}{c}\text { Unstandardized } \\
\text { Coefficients } \\
\text { S }\end{array}$} & $\begin{array}{c}\text { Standardized } \\
\text { Coefficients } \\
\text { Beta }\end{array}$ & T & Sig. \\
\hline $\begin{array}{c}\text { (Constant) } \\
\text { REGR factor } \\
\text { score 1 for } \\
\text { analysis 1 } \\
\text { REGR factor } \\
\text { score 2 for } \\
\text { analysis 1 }\end{array}$ & 2907,850 & 44,700 & & 13,598 & 0,000 \\
\hline
\end{tabular}

Tabel $6 . \quad$ Koefisien determinasi untuk bakteri Coliform

\begin{tabular}{ccccc}
\hline Model & $\mathrm{R}$ & $\mathrm{R}$ Square & Adjusted R Square & Std. Error of the Estimate \\
\hline 1 & $.862^{\mathrm{a}}$ & .743 & .713 & 199.906 \\
\hline
\end{tabular}

a. Predictors: (Constant), REGR factor score

2 for analysis 1, REGR factor score 1 for analysis 1 ,

b. Dependent Variable: Protozoa

\section{Pengaruh Faktor Kualitas Air Terhadap Cryptosporidium}

Tabel 3 merupakan hasil uji regresi yang dapat mengetahui hubungan kedua faktor utama terhadap keberadaan Cryptosporidium di hulu Sungai Citarum. Koefisien yang didapat akan dimasukkan ke dalam persamaan untuk mengetahui hubungan antara variabel bebas dengan variable tak bebas. Dari tabel tersebut juga didapatkan nilai siginifikansi masing - masing faktor. Nilai signifikasi untuk F1 dan F2 secara berurutan adalah 0,654 dan 0,648 . Nilai signifikasi kedua faktor tersebut tidak memiliki pengaruh terhadap keberadaan Cryptosporidium karena nilai signifikansinya melebihi 0,05.

Tabel 4 menunjukkan nilai koefisien determinasi $\left(r^{2}\right)$ yang didefinisikan sebagai kemampuan variabel bebas dalam menjelaskan varians dari variabel terikatnya. Nilai $r^{2}$ yang dihitung sebesar 
0,024 yang menunjukkan bahwa hanya $2,4 \%$ dari kedua faktor utama tersebut yang memiliki pengaruh atas keberadaan Cryptosporidium di Hulu Sungai Citarum.

Pengaruh Parameter Fisika dan Kimia Air Terhadap Bakteri Coliform

Bakteri Coliform memiliki faktorfaktor utama parameter fisikokimia yang sama dengan faktor-faktor utama fisikokimia pada Cryptosporidium. Setelah diidentifikasi, analisis tingkat pengaruh untuk faktor-faktor tersebut selanjutnya dilakukan.

Tabel 5 merupakan hasil uji regresi parameter fisika dan kimia air terhadap Coliform. Parameter air yang memiliki pengaruh signifikan adalah parameter DO, turbidity, COD, $\mathrm{NO}_{2}, \mathrm{NH}_{4}$ dan $\mathrm{PO}_{4}$. Hal ini dibuktikan dengan nilai signifikansi yang bernilai lebih kecil dari pada (>) 0,05 pada kedua faktor tersebut. Nilai signifikansi untuk faktor pertama sebesar 0,000 dan nilai signifikansi pada faktor kedua sebesar 0,016. Sedangkan, Tabel 6 menunjukkan bahwa kedua faktor tersebut memiliki pengaruh $71,3 \%$ terhadap keberadaan bakteri Coliform di perairan Hulu Sungai Citarum.

\section{KESIMPULAN}

Berdasarkan indeks kualitas air NSF-WQI, status kualitas air hulu Sungai Citarum termasuk kedalam kategori buruk hingga sedang yang disebabkan oleh pencemaran limbah organik dari kegiatan antropogenik masyarakat di sekitar Hulu Sungai Citarum. Parameter fisika dan kimia air yang memiliki hubungan yang signifikan dengan bakteri Coliform adalah DO, turbiditas, COD, $\mathrm{NO}_{2}, \mathrm{NH}_{4}$ dan $\mathrm{PO}_{4}$. Namun, korelasi antara parameter fisika dan kimia air dengan Cryptosporidium tidak signifikan. Terdapat dua faktor utama yang diduga memiliki pengaruh terhadap keberadaan Cryptosporidium, yaitu: 1) faktor pertama: DO, turbiditas, $\mathrm{NO}_{2}, \mathrm{NH}_{4}$ dan total Colifom, dan 2) faktor kedua: TSS, COD dan $\mathrm{PO}_{4}$. Namun, kedua faktor tersebut hanya memiliki pengaruh sebesar 2,4\% terhadap keberadaan Cryptsoporidium. Nilai yang dihasilkan ini menunjukkan bahwa keberadaan Cryptosporidium tidak dipengaruhi oleh kedua faktor tersebut. Sedangkan, pengaruh parameter fisika dan kimia air terhadap keberadaan bakteri Coliform memiliki persentase yang lebih tinggi dibandingkan dengan Cryptosporidium, yaitu sebesar $71,3 \%$.

\section{DAFTAR PUSTAKA}

APHA (American Public Health Association). 2012. Standard Methods For The Examination Of Water And Wastewater, $22^{\text {nd }}$ edition. USA

Atherholt, B. T., Lechavallier, W.M., Norton, D. W., Rosen, S. J. 1998. Effect of Rainfall on Giardia and Crypto. Waterbone Patogens, Journal of AWWA, Vol 90.

Baldurson, S., Karanis, P. 2011. Waterbone Transmission Of Protozoan Parasites: Review Of Worldwide Outbreaks-An Update 2004-2010. In: Water Research 45: 6603-6614

Muntalif, B.S., Ratnawati, K., dan Bahri, S. 2008. Bioassesment menggunakan Makroinvertebrata Bentik Untuk Penentuan Kualitas Air Sungai Citarum Hulu. Jurnal Purifikasi, 9(1): 49-60.

Fayer, R., Trout, J.M., dan Jenkins, M.C. 1998. Infectivity Of Cryptosporidium Parvum Oocysts Stored In Water At Environmental Temperatures. J. parasitol.,84:6:1165-1169.

Faza, M.F. 2015. Hubungan Kepadatan Populasi Makrozoobentos Sedimen Perairan Terhadap Parameter Kualitas Perairan Sungai (studi kasus: Sungai Citarum Hulu). Tesis. Bandung: Fakultas Teknik Sipil dan Lingkungan. ITB: Bandung

Hofstra, N., Bouwman, A.F., Beusen, A.H.W., Medema, G.J. 2013. Exploring Global Cryptosporidium Emissions To Surface Water. In: Science of The Total Environment 442: 10-19

Izzati, Munifatul. 2008. Perubahan Konsentrasi Oksigen Terlarut dan $\mathrm{pH}$ Perairan Tambak setelah Penambahan Rumput Laut Sargassum Plagyophyllum dan Ekstraknya. UNDIP: Laboratorium Biologi Struktur dan Fungsi Tumbuhan Jurusan Biologi FMIPA.

Lisle, J. dan Rose, J. 1995. Cryptosporidium Contamination Of Water In The USA and UK: a MiniReview. Water SRT-Aqua, 44:3:103117.

Marganof., Darusman, L.K.., Riani, F., Pramudya, B. 2007. Analisis Beban Pencemaran, Kapistas Asimilasi dan Tingkat Pencemaran dalam Upaya Pengendalian Pencemaran Danau Maninjau. Dalam: Jurnal Perikanan dan Kelautan 12, 1 (2007): 8-14

Oram, Brian. 2014. "Calculating NSF Water Quality Index. Water Testing, Monitoring The Quality of 
Surfacewaters". http://www.waterresearch.net/index.php/watertreatment/water-monitoring/monitoringthe-quality-of-surfacewaters. Accessed at 14 November 2014: 11.00 a.m.

Ott, W.R. 1978. Environmenta Indices: Theory and Practice. Ann Arbor Science. University of Michigan. ISSBN:0250401916, 9780250401918.

Republik Indonesia. 2001. Peraturan Pemerintah Republik Indonesia Nomor 82 Tahun 2001 Tentang Pengelolaan Kualitas Air Dan Pengendalian Pencemaran Air. Sekretariat Negara. Jakarta.
Srisuphanunt, M., Karanis,P., Charoenca, N., Boonkhao,N., Ongerth, J.E. 2010. Cryptosporidium and Giardia detection in Environmental Watersof Southwest Coastal Areas of Thailand. In:Springer:Parasitol Res106:12991306

Sunnotel, O., Lowery, C.J., Moore, J.E., Dooley, J.S.G., Xiao, L., Millar, B.,C. 2006. "Under The Microscope, Cryptosporidium" In:Journal Compilation, The Society for Applied Microbiology, Letters in Applied Microbiology: 43, ISSN 0266-8254 